\title{
URBANIZAÇÃO DE ASSENTAMENTOS PRECARIZADOS E DIREITO À CIDADE
}

\section{Urbanization of precarious settlements and the right to the city}

http://doi.org/10.17648/revistaterritorialidades-v1n1-1

\section{RESUMO}

Este texto abre o dossiê "Assentamentos precarizados: urbanização desigual e (re)apropriação do território". A apresentação está dividida em três tópicos. Inicialmente, revisamos a literatura que informa, de modo transversal, os históricos de ocupação territorial em algumas grandes cidades brasileiras, com atenção especial aos assentamentos precários. Em seguida, examinamos esses assentamentos como campo de disputas ligadas a demandas por direito à cidade e à moradia - tema que atravessa as contribuições deste dossiê. Por fim, introduzimos os artigos que integram esta primeira edição da Revista Territorialidades, apresentando os resumos articulados dos textos em relação à proposta epistemológica do dossiê.

Palavras-chave: Assentamentos Precarizados. Direito à Cidade. Direito à Moradia. (Re)apropriação do Território. Urbanização Desigual.
Lucas Amaral de Oliveira

Universidade Federal da Bahia (UFBA) E-mail: lucasoliveira.ufba@gmail.com Orcid: orcid.org/0000-0002-1272-4722

Maya Manzi Universidade Católica do Salvador (UCSAL) E-mail: maya.manzi@pro.ucsal.br Orcid: orcid.org/0000-0001-9357-3964

This text opens the dossier "Precarious settlements: unequal urbanization and (re)appropriation of the territory". The presentation is divided into three topics. Initially, we review the literature that informs, in a transversal mode, histories of territorial occupation in some of the large Brazilian cities, with special attention to precarious settlements. Next, we examine these settlements as a field of disputes linked to demands for the right to the city and to housing - a theme that runs through the contributions of this dossier. Finally, we introduce the articles that make up this first thematic edition of the Revista Territorialidades, presenting the articulated summaries of the texts in relation to the epistemological proposal of the dossier.

Keywords: Precarious Settlements. Right to the City. Housing Rights. (Re)appropriation of the Territory. Unequal Urbanization. 
Euclídes da Cunha, o retratista da Guerra de Canudos, talvez tenha sido quem primeiro flagrou o destino histórico da marginalização urbana no Brasil e, por conseguinte, da própria criminalização da pobreza. O escritor fluminese foi um dos primeiros a fazer uso do termo "favela". Em Os Sertões (1985), a palavra carrega uma acepção geográfica específica ao designar uma pequena colina (chamada de Alto da Favella), ao sul de Canudos, na Bahia, onde era comum uma planta euforbiácea, a Cnidoscolus Quercifolius, popularmente conhecida por "favella" (faveleiro, mandioca-brava). Trata-se de uma leguminosa, com espinhos e flores brancas dispostas em cimeiras (o fruto é semelhante às sementes de fava, o que pode ter originado o nome), encontrada em estados do nordeste brasileiro. Posteriormente, a palavra passará a designar, de maneira mais substantiva, os morros ocupados na cidade do Rio de Janeiro, sobretudo nas imediações da Central do Brasil.

Uma das hipóteses históricas - ou mitos de origem - sugere que alguns soldados que lutaram contra Antônio Conselheiro e seus seguidores, ao regressarem para a cidade do Rio de Janeiro, em 1897, sem os estipêndios que lhes foram prometidos pelo governo republicano, instalaram-se em construções provisórias à espera das recompensas pela campanha de massacre em Canudos. Essas construções constituíam casas autoconstruídas de madeira e zinco, sem traçado, arruamento e acesso a serviços, e ficavam próximas ao Ministério da Guerra (mais designadamente, no Morro da Providência). O local foi batizado, depois, como "Morro da Favella" (PENNA, 2015; VALLADARES, 2000).

Há outras duas hipóteses complementares que buscam dar conta da sociogênese da favela no contexto urbano brasileiro do final do século XIX. Uma defende que o aparecimento da favela enquanto forma habitacional específica tenha se dado em função do processo de desterritorialização por que passaram pessoas escravizadas, que trocaram sua alforria por uma participação "voluntária" na Guerra do Paraguai (1865-1870). Ao retornarem do conflito para a capital federal, sem estrutura financeira, social ou familiar que os pudessem abrigar, passaram a residir nas encostas de alguns morros próximos à região central do Rio Janeiro (CAMPOS, 2007). Outra hipótese atribui a ocupação "provisória" dos morros da Providência e de Santo Antônio à destruição do famoso Cortiço "Cabeça de Porco", em 1894, quando Barata Ribeiro, o então prefeito do Rio de Janeiro, travou uma verdadeira guerra higienista contra essa forma habitacional, acusando-a de abrigar pobres em uma região nobre da cidade e de constituir um "antro de vício", vagabundagem, marginalidade, crime e epidemia (VALLADARES, 2000). Assim, a relação entre o desmantelamento do histórico cortiço e o desenvolvimento inicial do Morro da Providência (depois, Morro da Favella) se dá através da remoção de cerca de 4 mil moradores, em sua grande maioria negros, que foram "autorizados" pelo prefeito a reutilizarem o material demolido dos cômodos em outras construções (CHALHOUB, 1996; VAZ, 1994).

Independentemente da precisão das três suposições sobre a emergência dessa forma de habitação popular que hoje se faz tão visível nas cidades brasileiras, Abreu (1998) e Valladares (2000) sugerem que, entre os anos 1920 e 1930, esse tipo específico de aglomerado de casebres autoconstruídos, sem planejamento e infraestrutura pública, passou a ser cada vez mais presente na paisagem dos grandes centros urbanos e industriais do país, vindo a se tornar um problema perene para os poderes locais. No mesmo período, a imprensa começou a associar o termo não apenas ao Morro da Favella, mas a uma nova categoria para designar as aglomerações "típicas" da população pobre, de ocupação "ilegal", geralmente localizadas em encostas. Essas histórias são indícios que a ocupação informal e irregular no país é resultado de um problema fundiário não resolvido, fruto de um sistema escravagista, cuja abolição nunca possibilitou às pessoas escravizadas libertas e a seus/suas descendentes a garantia de segurança de posse da terra.

O que se pode afirmar com mais precisão é que, entre os séculos XIX e XX, no processo de 
expansão e "modernização" acelerada das cidades brasileiras, os migrantes mais pobres (majoritariamente, pessoas negras) não tiveram condições de acesso às áreas regularizadas das cidades; logo, foram relegados às regiões de risco ambiental, desvalorizadas por serem impróprias à habitação e por estarem submetidas às intempéries das mais diversas. Áreas de risco foram, então, ocupadas por uma população historicamente marginalizada em termos de classe, raça, religião e estilo de vida, incluindo locais ambientalmente menos habitáveis do tecido urbano, como as encostas íngremes dos morros, as áreas alagáveis de fundo de vales, as áreas poluídas na beira de grandes rodovias que foram surgindo à medida que o país se industrializava, perto de aterros sanitários, de indústrias altamente poluidoras ou nos arrabaldes mais distantes e literalmente periféricos das cidades, ou seja, destituídas de qualquer infraestrutura ou serviço urbano.

Hoje, quase $90 \%$ da população brasileira vive em cidades. De 1950 a 2000, o país sofreu não apenas o êxodo rural que tanto marcou as chamadas economias periféricas do Sul Global, mas uma verdadeira "explosão urbana" (SILVA, 2012), ocorrida de forma acelerada, informal, sem controle e desordenada. Tal processo se caracterizou por um intenso fluxo migratório interno, formatado por enormes contingentes populacionais que se deslocaram para os centros industriais, comerciais e de serviços em busca de trabalho, moradia e melhores oportunidades de vida. O saldo foi um visível processo de segregação espacial, que se traduziu em padrões diferenciados de produção e ocupação do território, bem como em desigualdades sociorraciais gritantes. Atualmente, estima-se que $40 \%$ da população urbana brasileira resida em "domicílios inadequados"1, o que abrange tanto as "moradias precarizadas" (BONDUKI, 1998) quanto os chamados "aglomerados subnormais". Este último, em especial, é um termo consolidado em pesquisas sobre déficit habitacional no Brasil e, sobretudo, em levantamentos oficiais do Instituto Brasileiro de Geografia e Estatística (IBGE). A categoria contempla uma variedade ampla de assentamentos informais submetidos a condições precárias em termos de serviços e infraestrutura pública, nos quais estão incluídos, a depender da região, favelas, palafitas, baixadas, grotas, invasões, comunidades, morros, ocupações, ressacas, mocambos, loteamentos clandestinos, assentamentos irregulares, etc. Essa pluralidade de padrões e formas de apropriação do território urbano indica uma relação, às vezes tênue, outras vezes patente, entre a formalidade e a informalidade da configuração urbana no Brasil.

A história da ocupação informal no Brasil é reflexo do racismo ambiental a que parcela considerável da população foi submetida. Ou, se quisermos, da manifestação de um "racismo fundiário", nos termos de Tatiana Dias Gomes (2019), instituído por meio de uma complexa rede que viabiliza ações violentas de pessoas brancas contra corpos, culturas, saberes, espaços e bens ambientais de pessoas negras, indígenas e outras minorias racializadas. Essas ações se articulam na prática, sobretudo, através de formas político-jurídicas limitadoras e ceifadoras de cosmovisões não europeias, o que tem como consequência direta e indireta estrangulamentos orçamentários e políticas públicas que fortalecem os empreendimentos predatórios? ${ }^{2} \mathrm{Na}$

\footnotetext{
${ }^{1}$ De modo geral, os "domicílios inadequados" são aquelas habitações que sofrem com falta de saneamento básico, abastecimento de água encanada, coleta de lixo, fornecimento de energia e estrutura física habitável, geralmente construídas sem fundações sólidas ou muito distantes das áreas urbanas com ofertas de serviços e infraestrutura social. "Moradias precarizadas" são aquelas que, tecnicamente, para o Estado, carecem de uma ou mais das seguintes condições: 1) uma habitação durável de natureza permanente que proteja os/as residentes contra condições climáticas adversas; 2) um espaço vital suficiente, com não mais de três pessoas compartilhando um mesmo cômodo; 3) acesso fácil à água potável em quantidade suficiente para as necessidades elementares; 4) acesso a saneamento adequado, esgoto e banheiro privado ou público/compartilhado por uma quantidade razoável de pessoas; 5) posse segura e estabilizada, para evitar despejos forçados (UN-HABITAT, 2012, p. 64).

2 O racismo ambiental, parte do racismo estrutural, é um conjunto de injustiças sociais a que grupos racializados estão submetidos, o que faz com que seus territórios e suas formas de vida sofram desproporcionalmente os custos sociais, de um lado, de atuações desastrosas por parte do Estado e do mercado, de outro, da omissão de políticas públicas. Essas injustiças favorecem que no meio ambiente vigorem determinantes da desigualdade social e racial, resultando em iniquidades raciais, exploração política e enfrentamento de problemas ambientais por parte de comunidades negras (ACSELRAD; HERCULANO; PÁDUA, 2004; JESUS, 2020).
} 
formação do Estado nacional, o direito à terra e à moradia - o direito à propriedade -, um dos direitos constitucionais mais elementares, é, e segue sendo, uma questão de cor.

Indicadores recentes mostram que a desigualdade socioespacial no Brasil tem cor. Em levantamento recente do IBGE (BRASIL, 2019), verificou-se que uma maior proporção da população preta ou parda reside em domicílios sem coleta de lixo $(12,5 \%$, contra $6,0 \%$ da população branca), sem abastecimento de água (17,9\%, contra $11,5 \%$ da população branca) e sem esgotamento sanitário por rede coletora ou pluvial $(42,8 \%$, contra $26,5 \%$ da população branca), sendo que quase $45 \%$ da população preta ou parda vive em domicílios com a ausência de, pelo menos, um serviço de saneamento básico. Já entre os brancos, esse percentual é de $28 \%$. Isso tem como consequência uma condição de vulnerabilidade sanitária muito mais acentuada entre a população negra, que fica, portanto, mais exposta a vetores de doenças.

Como demonstra Ângela Maria Gordilho Souza (2001), quando observamos de forma panorâmica os diversos processos de urbanização por que passaram as maiores cidades brasileiras, é possível verificar que, guardando uma mesma característica da informalidade na ocupação habitacional, esses processos carregam peculiaridades em sua constituição, com resultados socioespaciais similares e, ao mesmo tempo, distintos. As similaridades decorrem, sobretudo, da prática da autoconstrução "ilegal” como mecanismo alternativo encontrado por populações pobres para reivindicarem seu direito à moradia, mesmo que à revelia do controle formal do Estado e do mercado. As diferenças, por sua vez, são resultado de planos urbanísticos específicos de cada cidade, que regulam o uso e a ocupação do solo, ao mesmo tempo em que impõem normas seletivas para os tipos de habitação em certas áreas urbanas, contribuindo para intensificar ainda mais o processo de segregação espacial da população pobre e racializada.

É importante entender a história de segregação socioespacial, favelização e periferização das cidades como produto de um longo processo de "acumulação por despossessão" (HARVEY, 2003) que ainda está em curso? A condição de "sem terra" e "sem teto", por exemplo, longe de uma condição natural ou voluntária, é resultado de um processo violento e sistemático de expropriação de parcelas subalternizadas e racializadas da sociedade brasileira de suas moradias rurais e urbanas, seja por parte do Estado, das elites nacionais ou regionais - concentradoras de riqueza e poder - ou pelo capital nacional e internacional ${ }^{4}$. Essas três esferas se imbricam e se reforçam de diversas formas. A usurpação do direito à moradia digna e ao acesso às benesses da cidade de uma parcela bem definida da sociedade se expressa urbanisticamente, sobretudo, mediante criação de periferias centrais (nas áreas ambientalmente vulneráveis mencionadas acima) e de periferias suburbanas, em áreas geograficamente distantes do centro da cidade, onde bens, infraestrutura e serviços urbanos são escassos ou inexistentes. Essa periferização, ou o que autores/as chamam de "padrão periférico" de ocupação do território (BONDUKI; ROLNIK, 1979; MARICATO, 2001), reproduz e exacerba as desigualdades sociorraciais entre a parte mais abastecida e a parte mais despossuída da sociedade brasileira.

Com um modelo de urbanização periférica consolidado - que absorveu contingentes

\footnotetext{
${ }^{3}$ Para Lúcio Kowarick (1979), em muitos centros urbanos, a alocação diferenciada de serviços e bens teve como saldo uma urbanização caótica e um alto grau de pauperização social, processo denominado por ele de "espoliação urbana". Trata-se de uma somatória de extorsões sistemáticas por parte do poder público e de setores privados, que se manifestam de duas maneiras: ou pela ausência total naqueles espaços, ou quando submetem as periferias à precariedade de serviços, espaços, bens e equipamentos, marginalizando suas populações vulnerabilizadas.

4 O termo "estrangeirização de terra" é usado quando a expropriação fundiária envolve o capital internacional. Lorena Izá Pereira (2019, p. 72) o define como um "processo de apropriação do território - multidimensional e multiescalar - por agentes (trans) nacionais, cujo objetivo é a alienação do território para atender as demandas do capital externo e para a garantia de sua acumulação".
} 
populacionais em poucos e grandes centros, sem, contudo, integrá-los devidamente à cidade -, na última década do século XX, testemunhamos a implantação de reformas neoliberais que atingiram sobremaneira as cidades brasileiras, especialmente a partir de 1994. Essas reformas levaram à fragilização de algumas pequenas conquistas anteriores - que vieram com a redemocratização do país e a Constituição Federal de 1988, por exemplo - e ao que Ermínia Maricato (2001) chamou, certa feita, de "urbanização da pobreza": predominância do trabalho precário, aumento da informalidade em centros urbanos, desemprego de longa duração, aprofundamento da expansão periférica, assentamentos irregulares, favelização. Em várias metrópoles, foi um período de empobrecimento e explosão demográfica nos aglomerados subnormais, em que projetos desastrados de renovação urbana baniram milhões de moradores dos centros para seus arrabaldes periféricos.

É preciso dizer, por fim, que, na história mais recente do país, algumas políticas públicas habitacionais visaram corrigir o problema histórico de déficit habitacional no Brasil, como "Minha Casa Minha Vida". Mas, ao mesmo tempo, essas mesmas iniciativas contribuíram para dilatar o processo de periferização da população historicamente marginalizada. Além disso, não houve uma preocupação com o corte racial da questão urbana no país. A maioria dos conjuntos habitacionais construídos no âmbito do programa, bem como de outras iniciativas nas esferas estaduais e municipais, a fim de atender a população com baixa segurança habitacional, foi alocada em áreas distantes dos centros das cidades, sem acesso a bens e serviços urbanos - como transporte público. Enquanto isso, permanecem inúmeras áreas vazias ou subutilizadas nos centros urbanos, fazendo com que a função social da propriedade e da própria cidade, estipulada na Constituição (1988) e no Estatuto da Cidade (2001), não sejam cumpridos.

As políticas e práticas de urbanização são parte e parcelas de uma conformação nacional racista e violenta que continua produzindo injustiças e desigualdades; mas não sem contestação e muita resistência dos grupos sistematicamente prejudicados pelo sistema e dos seus aliados. Logo, ao falarmos de urbanização desigual, processos de segregação socioespacial, urbana e racial, favelização e assentamentos precarizados, é preciso ter em vista sua contra-parte: as lutas por terra e moradia, que estão dentro de uma afirmação de que a cidade é um direito social. Ou seja, as políticas de segregação, precarização e despossessão são corriqueiramente confrontadas e contestadas por movimentos e práticas de resistência, de (re)apropriação do território e de contra-uso do espaço urbano. Muitos desses movimentos lembram a todos/as nós, acadêmicos e pesquisadores da questão urbana, da necessidade de reafirmarmos a importância de refletir a cidade como território plural, público e sempre mais inclusivo. Afinal, a expansão da urbanização foi capaz de criar um tecido urbano fragmentado, diferenciado, contraditório e excludente; mas, ao mesmo tempo, muito indiciário e aberto para o futuro.

Essa é uma das apostas deste dossiê, cujo primeiro objetivo é tensionar, na linha de David Harvey (2012) e Henri Lefebvre (2001 [1968]), o direito à cidade e à moradia tanto como um lema operacional, quanto como um ideal político. Trata-se de pensar a cidade não enquanto algo estático, neutro, uma entidade imóvel e dada previamente. A cidade é algo que se encontra interligada com o tempo e os/as agentes que a produzem, cotidianamente; por este motivo, está sempre em transformação. Cidade é mudança. Pensar o território da cidade é pensar em dinâmicas. Para Doreen Massey (2005), a cidade deve ser interpretada, de um lado, como um território físico que recebe pessoas, mas, de outro, como um produto das inter-relações humanas, vale dizer, esfera da possibilidade de existência entre "diferentes", arena dos novos direitos e novas cidadanias. Portanto, é o espaço de subversão, de criação, e de transformação.

\footnotetext{
5 Foram reformas voltadas ao mercado financeiro, que incluíram a abertura comercial, a liberalização do regime de investimentos estrangeiros, as privatizações de serviços públicos e de empresas estatais e a desregulamentação do mercado de trabalho e serviços, com a redução drástica de direitos, o abandono das instituições de seguridade social e o aumento da prática de terceirização e da subcontratação. Sobre isso, cf.: Boito Jr. (1999) e Harvey (2002).
} 
O segundo objetivo deste dossiê é refletir sobre a fronteira porosa entre o que é considerado e instituído como "legal" ou "ilegal", que, no Brasil, acaba sendo uma questão de classe e raça, como vimos anteriormente. A criminalização da pobreza contrasta e contradiz a legitimação da criminalidade nas esferas do poder político e econômico. O mercado imobiliário no país tem mantido o privilégio perante o Estado de se posicionar livremente acima ou à revelia da lei. É nessa nebulosa fronteira da (il)legalidade que uma empresa multimilionária logra obter do Estado o "direito" de construir (ilegalmente) um condomínio de luxo em área de proteção ambiental e paisagística, ao passo que um ocupante pobre que (legalmente) estaria contribuindo para a função social da propriedade e da cidade é removido (ilegalmente) para dar espaço à especulação imobiliária. Essa normalização da suspensão do estado de direito - o chamado "estado de exceção" (AGAMBEN, 2004) -, aplicada à questão urbana, é o que caracteriza os processos de urbanização neoliberal de boa parte das cidades brasileiras contemporâneas (VAINER 2011). Foi nesse sentido que o sociólogo Francisco de Oliveira (2003, p. 9) afirmou que, se historicamente as relações entre o Estado e o urbano se pautaram "por um esforço de normatividade da relação capital-trabalho, cabendo ao planejamento enquadrar a exceção e transformá-la em norma, transformações radicais recentes na economia e sociedade brasileiras sugerem que a exceção parece ter enquadrado o planejamento".

As distintas características históricas, socioeconômicas e culturais das cidades brasileiras, que foram submetidas a diferentes formas de produção e apropriação do território urbano, resultaram em configurações espaciais próprias, sendo que muitas delas permitem que a exceção se torne a nova regra do planejamento urbano. Essas especificidades exigem dos/as diversos/as agentes envolvidos/as análises situadas no tempo e no lugar, para que possamos conjuntamente pensar em projetos de mudança. Assim, o terceiro objetivo deste dossiê é oferecer perspectivas situadas sobre urbanização e (re)apropriação do território, a partir de disputas materiais e simbólicas em "assentamentos precarizados" de várias cidades do Brasil.

A aposta deste dossiê é que há uma lógica dupla marcando a questão urbana no país: a disjunção entre os princípios do mercado e a dinâmica societária. De um lado, há os imperativos de eficácia da economia monetária aplicada ao planejamento das cidades; de outro, a exigência de mais direitos por parte de movimentos sociais e culturais de caráter urbano. Os processos de urbanização desigual no país são abordados de forma crítica e diversa em todos os artigos desta primeira edição. Os textos se debruçam sobre os contextos históricos e geográficos nos quais esses processos ocorrem; mas também contemplam agentes, instrumentos e práticas envolvidas nesses processos, bem como suas implicações sociais, econômicas, espaciais e ambientais, nunca perdendo de vista as intersecções e diferenciações em termos de classe e raça. Em especial, algumas contribuições examinam mais a fundo os impactos de intervenções urbanas que reestruturam, revitalizam, privatizam ou mercantilizam áreas historicamente desvalorizadas da cidade, avaliando suas implicações tanto em termos urbanísticos e de planejamento quanto em termos de justiça socioambiental. Outros salientam as práticas de resistência e contraposição dos grupos marginalizados às intervenções segregacionistas do Estado neoliberal, quase sempre a serviço do setor imobiliário.

\section{III}

Laura Machado de Mello Bueno, Taís Economides Gallina e Simone Bandeira de Souza, em "A água tem lugar na cidade? Estudo de uma microbacia hidrográfica urbanizada em Campinas (SP)", analisam os impactos da remoção de moradias em áreas de risco ambiental e sua realocação em conjuntos habitacionais distantes do seu lugar de origem. Os resultados alcançados mostram que, além de quebrar os laços sociais dessas comunidades e comprometer o modo de vida dos seus habitantes, a recuperação ambiental e urbanística das áreas de risco após a remoção permanece insuficiente e inadequada. Proposições de intervenção urbanística e de gestão da bacia são apresentadas pelas autoras, no sentido de promover a reintegração do rio 
à paisagem e funcionalidade urbana, contribuindo para a sustentabilidade urbana e justiça ambiental.

O artigo de Debora Moraes Ferreira e Flavia de Sousa Araújo, "Além da linha do horizonte: delineando a urbanização da Grota Poço Azul em Maceió (AL)", também mostra a importância de repensarmos a relação "natureza-sociedade" dentro do contexto urbano, por intermédio de programas e práticas que legitimem e promovam o direito à moradia digna e de qualidade em áreas de risco, como é o caso das grotas em Maceió, áreas ocupadas de forma irregular pelos setores mais pobres da população. As autoras argumentam que é necessário dar visibilidade à existência das grotas através do seu reconhecimento legal como "Zona Especial de Interesse Social" (ZEIS). Para tanto, propõem intervenções urbanas localizadas que possam promover sua habitabilidade, segurança e sustentabilidade. Nessa medida, o estudo, que é propositivo, volta-se para uma prática contra hegemônica de ocupação do território urbano.

A importância crescente conferida ao fenômeno espacial-urbano nas últimas décadas deve-se ao fato de que a cidade teria se convertido em uma arena de conflitos que vai além das disputas meramente políticas, englobando também as disputas simbólicas (BRENER, 2013; MASSEY, 2005; PARDUE; OLIVEIRA, 2017). Logo, a (re)apropriação do espaço urbano não é um processo apenas material, podendo ocorrer de forma imaterial. Tal dimensão é ressaltada por Miguel Bustamante Nazareth, em "A 'Favela Urbanizada': memórias de uma história comum", em que o autor analisa as disputas territoriais e as formas de (re)apropriação do espaço por seus habitantes, tomando como caso empírico uma "favela urbanizada" de São Paulo. A partir de métodos qualitativos, o autor analisa narrativas, memórias e representações do espaço no plano do vivido, mostrando como, através de múltiplas territorialidades, a "favela urbanizada" é produzida e tensionada, material e simbolicamente, com todos os seus paradoxos.

A história dos assentamentos precarizados no Brasil impõe um desafio, tanto para as políticas de intervenção e os projetos de "melhorias habitacionais", do lado de agentes estatais que visam a inclusão de áreas de insegurança habitacional à regularidade fundiária, quanto para os movimentos da sociedade civil organizada, envolvidos na luta por moradia e, atualmente, pelo direito à cidade. Consequentemente, isso exige dos campos da geografia, da arquitetura, do urbanismo, do planejamento, mas também das ciências sociais e das ciências ambientais, um esforço combinado.

Nesse sentido, em contraste com o longo processo de "urbanização da favela" apresentado no artigo de Nazareth, o artigo "O espaço minado das 'melhorias habitacionais': individualismo, autoridade e dominação", de Frederico Lago Burnett, examina o processo pontual e eficiente dos programas de "melhorias habitacionais" em bairros populares, problematizando como seu caráter individualista, ou seja, restrito à esfera privada da família, compromete a potencialidade emancipatória e transformadora dos projetos. O autor mostra como esses programas de melhorias operam mediante o empreendedorismo social promovido pelo Estado neoliberal e do seu entrelaçamento com o velho clientelismo brasileiro, reproduzindo valores conservadores.

O artigo de Burnett, com seu foco crítico na racionalidade capitalista que fundamenta os novos programas de assistência à moradia popular, dialoga de forma produtiva com o artigo de Fausi Kalaoum e Isabela de Fátima Fogaça, "Favela: produto cultural e turístico do município do Rio de Janeiro (RJ)?", na qual a favela é problematizada como uma commodity do capital turístico. A valorização da favela como destino turístico se dá pelos seus atrativos ecológicos (praia, parques, paisagens pitorescas) e culturais (festas, entretenimento, diversidade cultural), diferente de um turismo de pobreza. Os/as autores/as explicam como o turismo na favela não tem trazido impactos positivos relevantes para os/as moradores; em vez disso, tem levado a um processo de gentrificação e exclusão da população local em eventos, festas e espaços usados por turistas. O artigo ainda lança luzes sobre a relação entre segurança pública, turismo e especulação imobiliária, mostrando como a dinâmica de valorização e desvalorização da favela 
está diretamente ligada à instabilidade da segurança local. Isto pode revelar como o sistema de segurança pública é parte integrante do "racismo estrutural" (ALMEIDA, 2018) e, consequentemente, da produção e reprodução das desigualdades socioespaciais no Brasil.

Outra prática do Estado que traz contradições em suas implicações sociais, econômicas e ambientais são os projetos de regularização fundiária em assentamentos precarizados. Karen Alessandra Solek Soares, Fabíola Castelo de Souza Cordovil e Marilda Thomé Paviani, em "A urbanização de um assentamento precário: o caso do loteamento Melissa, em Cascavel (PR)", debruçam-se sobre um processo de urbanização local operado pelo Estado no âmbito do Plano Municipal de Habitação (PMH) e vinculado ao Programa de Aceleração do Crescimento (PAC), que visava promover investimentos públicos e privadas em infraestrutura urbana para estimular o crescimento econômico do país. No artigo, as autoras trazem à tona a questão da relação entre a legalidade e a ilegalidade com suas fronteiras tênues e suas contradições. Os resultados mostram como a tentativa de regularizar assentamentos precários têm tido, como efeito negativo, o aumento da degradação ambiental por promover a ocupação de área verdes em fundo de vale, que são áreas ambientalmente frágeis e consideradas impróprias à habitação.

Outro tema que perpassa todos os artigos deste dossiê é o do "direito à cidade", o qual inclui o direito, mais específico, à moradia digna. Lefebvre (2001) define o "direito à cidade" como uma prerrogativa do/a citadino/a de se (re)apropriar da cidade, de todos os seus espaços, bens e serviços, e então ressignificá-los a partir da dinâmica social que é, no limite, a tecedora da vida urbana. Trata-se do direito do/a habitante de se (re)apropriar de algo que lhe foi usurpado historicamente. Assim, o direito à cidade também pode ser entendido como direito à reparação.

É nesse sentido que caminha o artigo de Lais Granado, Jean Pierre Crété e Daniela Florpara, "Athis em Santos (SP): análise da aplicação das leis de assistência técnica", que advogam pela necessidade de se fazer garantir a aplicação da Lei Municipal $n^{\circ}$ 2.211/2004, sobre Assistência Técnica para Habitação de Interesse Social (ATHIS), no município de Santos. O município, que serve como estudo de caso, apresenta desigualdades socioespaciais que se manifestam em assentamentos irregulares e precários em morros, cortiços e palafitas, abrigando milhares de famílias em situação de vulnerabilidade. Os/as autores/as apontam medidas para aumentar a eficácia dessa lei e, com efeito, garantir o direito à moradia digna da população.

O tema da assistência técnica em territórios populares como forma de alcançar o direito à moradia e o direito à cidade é também abordado por Flavia Garofalo Cavalcanti, em "Uma perspectiva da assistência técnica em arquitetura a partir da estratégia de saúde da família nos territórios populares". No texto, a autora mostra como a função de mediadora da agente comunitária de saúde, com a sua dupla posicionalidade de cidadã/funcionária do Estado, se pensada de forma integrada com a atuação da arquiteta ou urbanista, pode suscitar novas formas de agir no território para superar conhecidas limitações de projetos de urbanização e regularização de assentamentos precários. A partir dessa reflexão epistemológica, o artigo também mostra a importância de pensar a ideia de "melhoria habitacional" na sua dimensão territorial específica, no sentido de considerar o cotidiano da sua implementação com base nas dinâmicas locais e nas territorialidades da população beneficiária.

\section{REFERÊNCIAS}

ABREU, Regina. O enigma de “Os Sertões”. Rio de Janeiro: Funarte/ Rocco, 1998.

ACSELRAD, Henri; HERCULANO, Selene; PÁDUA, José Augusto (org.) Justiça ambiental e cidadania. Rio de Janeiro: Relume Dumará, 2004.

AGAMBEN, Giorgio. Estado de exceção. São Paulo: Boitempo, 2004.

ALMEIDA, Silvio. O que é o racismo estrutural? Belo Horizonte: Letramento, 2018.

BOITO JR., Armando. Política Neoliberal e Sindicalismo no Brasil. São Paulo: Xamã, 1999. 
BONDUKI, Nabil. Origens da habitação social no Brasil: arquitetura moderna, Lei do Inquilinato e difusão da casa própria. São Paulo: Estação Liberdade/FAPESP, 1998.

; ROLNIK, Raquel. Periferia: ocupação do espaço e reprodução da força de trabalho. São Paulo: Fundação para a Pesquisa Ambiental, 1979.

BRASIL. Instituto Brasileiro de Geografia e Estatística. “Desigualdades sociais por cor ou raça no Brasil". Estudos e Pesquisas: Informação Demográfica e Socioeconômica, n. 41, 2019. Disponível em: biblioteca.ibge.gov.br/ visualizacao/livros/liv101681_informativo.pdf. Acesso em: 03 set. 2020.

BRENNER, Neil. Theses on Urbanization. Public Culture, v. 25, n. 1, p. 85-114, 2013.

CAMPOS, Andrelino. Do quilombo à favela: a produção do "espaço criminalizado" no Rio de Janeiro. Rio de Janeiro: Bertrand Brasil, 2007.

CHALHOUB, Sidney. Cidade febril: cortiços e epidemias na corte imperial. São Paulo: Companhia das Letras, 1996.

CUNHA, Euclides da. Os Sertões. São Paulo: Brasiliense, 1985.

GOMES, Tatiana Dias. Racismo Fundiário: a elevadíssima concentração de terras no Brasil tem cor. Disponível em: https://cptba.org.br/racismo-fundiario-a-elevadissima-concentracao-deterras-no-brasil-tem-cor/. Acesso em: 24 maio 2019.

HARVEY, David. Condição Pós-Moderna. São Paulo: Edições Loyola, 2002.

The New Imperialism. Oxford: Oxford University Press, 2003.

O direito à cidade. Lutas Sociais, São Paulo, n. 29, p. 73-89, jul./ dez., 2012.

JESUS, Victor de. Racializando o olhar (sociológico) sobre a saúde ambiental em saneamento da população negra: um continuum colonial chamado racismo ambiental. Saúde e Sociedade, v. 29, n. 2, e180519, 2020.

KOWARICK, Lúcio. Espoliação urbana. São Paulo: Paz \& Terra, 1979.

LEFEBVRE, Henri. O direito à cidade. São Paulo: Centauro, 2001.

MARICATO, Ermínia. Brasil, cidades: alternativas para a crise urbana. São Paulo: Vozes, 2001.

MASSEY, Doreen. For Space. London: Sage, 2005.

OLIVEIRA, Francisco de. O Estado e a Exceção ou o Estado de Exceção? Revista Brasileira de Estudos Urbanos e Regionais, Rio de Janeiro, v. 5, n. 1, p. 9-14, 2003.

PARDUE, Derek; OLIVEIRA, Lucas Amaral de. Apresentação: Direito à cidade problema teórico e necessidade empírica. Plural, São Paulo, v. 25, n. 2, p. 1-19, 2017.

PENNA, João Camillo. "Jagunços, topologia, tipologia (Euclides e Rosa)". In: FARIA, Alexandre Graça et al. (org.) Modos da margem: figurações da marginalidade na literatura brasileira. Rio de Janeiro: Aeroplano, 2015. p. 46-75.

PEREIRA, Lorena Izá. Estrangeirização da terra no Brasil: notas teóricas e metodológicas. Revista Eletrônica da Associação dos Geógrafos Brasileiros - Seção Três Lagoas, n. 29, ano 15, p. 71-91, 2019.

SILVA, Érica Tavares. Estrutura urbana e mobilidade espacial nas metrópoles. Rio de Janeiro: Letra capital, 2012.

SOUZA, Ângela Maria Godilho. Favelas, invasões e ocupações coletivas nas grandes cidades brasileiras: (Re)Qualificando a questão para Salvador-BA. Cadernos Metrópole, São Paulo, v. 5, p. 81-116, 2001.

UN-HABITAT. State of Latin American and Caribbean cities 2012: Towards a new urban transition. Nairobi, Kenia: UN-Habitat, 2012. Disponível em: https://unhabitat.org/state-oflatin-american-and-caribbean-cities-2. Acesso em: 07 set. 2020.

VAINER, Carlos. Cidade de exceção: reflexões a partir do Rio de Janeiro. In: ENCONTRO DA ASSOCIAÇÃO NACIONAL DE PÓS-GRADUAÇÃO E PESQUISA EM PLANEJAMENTO URBANO E REGIONAL (ANPUR), 14., 2011, Rio de Janeiro. Anais [...]. Rio de Janeiro: Anpur, 2011, p.1-15. 
VALLADARES, Licia. A gênese da favela carioca. A produção anterior às ciências sociais. Revista Brasileira de Ciências Sociais, São Paulo, v. 15, n. 44, out. 2000.

VAZ, Lilian Fessler. Dos cortiços às favelas e aos edifícios de apartamentos: a modernização da moradia no Rio de Janeiro. Análise Social, Lisboa, v. 24, n. 127, p. 581-97, 1994.

\section{INFORMAÇÕES DOS/AS AUTORES/AS}

\section{Lucas Amaral de Oliveria}

Doutor em Sociologia pela Universidade de São Paulo. Professor Adjunto do Departamento de Sociologia da Universidade Federal da Bahia. Coordenador do PERIFÉRICAS - Núcleo de Estudos em Teorias Sociais, Modernidades e Colonialidades.

E-mail:lucasoliveira.ufba@gmail.com

Orcid: orcid.org/0000-0002-1272-4722

Lattes: lattes.cnpq.br/0974813858531390

\section{Maya Manzi}

Doutora em Geografia pela Clark University, Estados Unidos. Professora e pesquisadora do Programa de Pós-graduação em Planejamento Territorial e Desenvolvimento Social da Universidade Católica do Salvador (PPTDS-UCSAL) e do Programa de Graduação em Geografia da UCSAL. Integra a Rede de Pesquisadores em Geografia (Socio)Ambiental (RP-G(S)A) e coordena o Grupo de Pesquisa em Ecologia Política, Desenvolvimento e Territorialidades (GP-EPDT).

E-mail: maya.manzi@pro.ucsal.br

Orcid: orcid.org/0000-0001-9357-3964

Lattes: lattes.cnpq.br/8503991514615478

Recebido em 01/06/2020

Aceito em 01/07/2020 